\title{
Future Doctors' Professional Competence Formation in Medical Universities with Innovative Pedagogical Technologies
}

\author{
Yaroslava Kulbashna ${ }^{1}$, Skrypnyk Iryna르, Valeriya Zakharova ${ }^{3}$ \\ ${ }^{1}$ Surgical Dentistry and Maxillofacial Surgery Department, Bogomolets National Medical University, Kyiv, Ukraine \\ ${ }^{2}$ Orthodontic Department, Bogomolets National Medical University, Kyiv, Ukraine \\ ${ }^{3}$ Foreign Languages' Department, Bogomolets National Medical University, Kyiv, Ukraine \\ Email: j.kulbashna@gmail.com, irynaskrypnyk@gmail.com, valerieozakharova@gmail.com
}

How to cite this paper: Kulbashna, Y., Iryna, S. and Zakharova, V. (2019) Future Doctors' Professional Competence Formation in Medical Universities with Innovative Pedagogical Technologies. Open Journal of Social Sciences, 7, 231-242. https://doi.org/10.4236/jss.2019.73020

Received: February 25, 2019

Accepted: March 10, 2019

Published: March 13, 2019

\begin{abstract}
The article considers the formation of professional competence in future dentists with the introduction of innovative pedagogical technologies into educational process of dental students. The benefit of these technologies for main of general and specific competencies, particularly for critical/clinical thinking formation, was substantiated and proved by the results of conducted experiment which are presented in the article.
\end{abstract}

\section{Keywords}

Pedagogical Technologies, Innovative Pedagogical Technologies, Future

Dentists, Professional Competence Formation, Medical Education,

Competency-Based Approach

\section{Introduction}

The most important task of reforming education in Ukraine is the training of an educated, creative person, ready to provide the needs of society in professional activities both at the national and international levels. This is facilitated by the introduction of a competency-based approach to modern higher education and the formation of professional competence of future specialists as an indicator of quality of received education [1]. Ukrainian scientists consider elaborating and applying of modern pedagogical technologies as one of the main conditions necessary for the development of a future specialist [2]. Their implementation is supposed to be one of the most important tasks of modern education which can facilitate the management of the learning process [3]. Current requirements de- 
mand from university teachers to reach a whole new level of educational material presentation; therefore, in addition to traditional technologies, they are ready to introduce modern pedagogical ones. It occurs due to the reforming of the higher education and the labor market requirements that are set to graduates and encourage them to move from accumulation of knowledge to the ability of operating them effectively, from "education for the rest of the life" to a continuous learning, from collective learning organization to the individual one. This leads to a renovation of professional training and is it is closely interconnected to the fundamental changes in education in the context of a competency-based approach that take place in near and far abroad [4]. In addition, teachers of specialized subjects increasingly feel the need to put into effect such technologies that would help to implement a personal approach to the student, since it is an essential component of developing future dentists' professional competence. Mentioned above tendencies in the development of modern professional training update further researches on new pedagogical technologies introduction into different fields of education, particularly into the medical branch [5].

Taking into consideration all mentioned above, the purpose of the article is to consider the modern pedagogical technologies applied to form critical and as a result-clinical thinking, which is the crucial part of the future specialists' professional competence formation in medical universities and to substantiate the feasibility of their application in dental education.

\section{Overview of Scientific Sources Related to the Issue of Innovative Pedagogical Technologies}

The development and use of modern pedagogical technologies are considered as one of the main conditions for facilitating the effectiveness of students' training for their future professional activity [3] [6] [7] [8] [9] [10]. The perfect model of learning material acquisition is based on the systematic effective interaction of participants in the pedagogical process. Its ultimate goal is to master all aspects of training, which are defined as the competencies that provide further effective self-development and self-improvement throughout the period of professional activity [5]. However, it is obvious that there is an industrial priority in the choice of pedagogical technologies. It is also related to the medical field, taking into account the specificity of teaching, which combines the theoretical and practical components of the educational process in the clinical sector of subjects during bedside teaching in the medical institution.

A thorough and comprehensive analysis of the phenomenon and the concept of "pedagogical technology" reveals that the conditions for the development of intelligence and creative skills of the individual, preparation for life in an open society, independent interaction with the dynamic world of professional activity depend not only on the content of education but on the educational technologies used in the process of learning [3]. But comprehensive understanding of their meaning is impossible without comparative analysis of the traditional technologies and theoretical substantiating of necessity to update the content. The term 
"pedagogical technology" has become extremely widespread in the system of higher education. However, there is no definite interpretation of this concept in pedagogical theory and practice. At the same time, there are dozens of approaches to the definition of "pedagogical technology". Such diversity of opinions caused by complexity and versatility of the outlined issue. Besides, there are some peculiarities of pedagogical technologies choice for different levels of education [9].

Pedagogical technology should meet such basic methodological requirements (technological criteria):

1) Conceptuality consists in relying on a scientific concept that justifies the achievement of educational goals from the philosophical, psychological, didactic, socio-pedagogical points of view.

2) Systematicity is confirmation of the system's signs: the logic of the process, the interconnection of all components, integrity. It provides diagnostic purpose-setting, planning, design, variability of methods and tools for correction of results.

3) Effectiveness is guaranteeing the achievement of the corresponding result of training at the optimal spend [7].

There are four levels in the structure of pedagogical technologies: 1) conceptual (theoretical); 2) technological (organization of the educational process); 3) procedural (particular actions); 4) technical (available means of training, in particular, technical ones) [11]. At the same time regardless the choice, pedagogical technologies must meet the following requirements: the setting of a cognitive task; ensuring of training material content presentation; assessing academic achievements due to technology use; implementing already acquired initial knowledge in order to form a higher level of scientific knowledge; providing the basis for further progressive development. Consequently, technology, unlike method, does not assume variability, any element cannot be missed. Constant feedback, correction and changes in future activities are mandatory for technologic training. It requires constant control of the students' approach to planned goals; monitoring students' work implies an appropriate correction of the learning process. In addition, the peculiarity of pedagogical technology consists in assisting of the educational process construction which guarantees the achievement of the set goals. The success of pedagogical technology implementation depends on the effective interaction of the participants in the pedagogical process and, in a greater degree, on the teacher's pedagogical excellence [7].

In the theory of pedagogy, there are different traditional teaching technologies (explanatory-illustrative, problem based learning, programmed-differentiated and combined ones) which, in the opinion of scientists, do not contribute to the development of thinking, logical and creative skills and innovative [5]. Although, it is obvious that the established path of direct transfer of knowledge on professional activity provided its successful acquisition, the fast-moving changes in modern society require other approaches oriented towards the result of the received education which is expressed in the competences (constituents of the 
professional competence of future specialists). In pedagogical science newly appeared phenomena like "modern innovations", "innovative technologies", "new technologies of learning", "interactive methods of teaching" require a detailed study [11]. The essence of these innovations demands the rejection of established stamps, stereotypes in teaching, education and personality development. This contributes to their widespread introduction because of the educational paradigm change from the knowledge productive to effective. The main objective of innovative education is assumed in provision of well-rounded human development. Innovation is introduced through interactive teaching methods that provide the following logic and sequence of learning activities: motivation, formation of new experience, its awareness through application, reflection [9].

The following types of the innovative learning technologies can be distinguished:

1) information technologies which aimed at the development of knowledge, abilities and skills;

2) operational technologies which form the ways of mental activity;

3) emotional and artistic and emotional-moral technologies which improve the spheres of aesthetic and moral relations;

4) self-development technologies form self-managing mechanisms of personality;

5) heuristic technologies develop creative abilities;

6) applied technologies help develop a practical sphere [12].

Thus, the analysis of scientific sources has evidenced about the existence of a variety of innovative technologies and the means of their implementation into higher education. However, technologies that characterize the industrial features of this process have not been considered yet. Consequently this issue requires thorough research in the context of future professionals competence formation.

\section{Innovative Technologies That Contribute to Future Dentists' Professional Competence Formation in Medical Universities}

Various types of innovative teaching technologies are described and investigated in higher education [11] [12] [13], [14], [15]. Analysis of scientific sources and own pedagogical experience allows to identify those pedagogical technologies which contribute greatly to the future dentists' professional competence formation.

1) Personally oriented (anthropocentric) technology is a scientifically substantiated influence on a student in order to maximize the comfortable conditions for the personal fulfillment and comprehensive development of his personality aimed at forming self-identification, self-determination, self-realization, solution of problems on his own, both in the typical and non-typical professional situations. This technology promotes the formation of competences like self-guided work; problem solving.

2) Developing technology is based on the principles of purposefulness in de- 
termining the ways of the problem solving. Particularly in medicine, it induces self-research activity to find the best methods of examination, treatment of the patient with the involvement of all possible sources. It provides development of competencies like analysis and synthesis of information; self-guided work.

3) Group technology is applied through the use of situational role plays. In medical field, one of the examples is a role play "doctor-patient" where a part of the students represents the patient; the other ones represent the doctor in the process of their relationship. Another variation of this role-play is an activity-"rescue team".

"Rescue team" is students' performance where the group of three persons is organized in emergency medical situation for immediate help and care. There is one leader and two participants-the leader gives instructions to the participants, after that they change their roles. It is extremely important according to Tuning project which states that the students have to be practically and psychologically prepared for their future roles in society, especially in nontypical situations [16]. By conducting such kind of activity, students are involved during the class in simulating tense professional situations where they can start applying both vocabulary and professional knowledge. In this way it is possible to form not only professional competence but foreign language one as well. Moreover, the activity is designed to form students' leadership competence which is vitally important for a future doctor as it is considered as maturity to take responsibility for themselves and for the whole group of people; that is why, the role of ability to work in a team, especially in international one, increases [17]. And vice versa, the absence or poor level of confidence may lead to the number of negative phenomena: psychological disorders such as anxiety, lack of self-confidence, frustration, depression, inferiority complex, tension inside the community, decrease of working capacity [1]. Such activities help form the competencies of interpersonal communication and teamwork.

4) Formation of a creative personality deals with implanting future specialists to use elements of creativity in the problem solving: the search for similar situations, the ability to compare, express their own assumptions and analyze them, etc. This technology encourages inducing new ideas.

5) Learning through research is especially effective in the study of natural sciences, in particular medical one, because they have many objects and phenomena that can be investigated. It develops the critical thinking that becomes the basis for clinical thinking formation in medical education. Acquisition of research competence occurs through experiments conducting, processing of results, etc. to educational-cognitive, scientific-cognitive and research work.

6) Brainstorming/Synectics technology consists in solution of particular problems by a group with the help of metamorphic thinking, brave hypotheses, intuitive solutions, "false" ideas. This technology of brainstorming has existed since 1960. It allows expressing new ideas without being criticized. This technique is usually successfully applied during different games that can be elaborated for professional vocabulary competence formation in future dentists. Professional 
vocabulary competence plays a key role in professional English competence formation. Vast majority of professional vocabulary is medical terminology which is necessary to be mastered by future dentists. The game technology, based on Cambridge methods of English language teaching, allows to apply new methods taking into consideration the peculiarities of professional terminology and process of new words remembering. Thus, offered technology provides opportunities for dental students not only to memorize new terms and professional related vocabulary, but also use them in appropriate context. It can help dental students in developing professional speaking skills [4].

At the dental department of Bogomolets National Medical University, brainstorming is successfully applied in the form of "Brain-ring". Analysis of the experience of educational process organization shows that this technology is successfully implemented in the form of a "brain-ring" at the dental faculty of Bogomolets National Medical University, where students are offered complex tasks that require the application of knowledge from different branches of medicine. During this game each student has an opportunity to express personal vision of his solution, to listen to the ideas of others, to discuss their shortcomings and advantages. It stimulates future dentists to in-depth study of material, its reviewing, systematizing and integrating. This technology helps develop the students' ability to support their own ideas, listen to the proposals of others, criticize the wrong approaches to tasks solving and take up an active position in life which is especially important for future doctors. Every experienced physician, especially surgeon, is familiar with the situation where neither knowledge nor experience help in a difficult and even critical situation, and only the intensity of intelligence, a quick response in the form of an integrative combination of all once and somewhere heard and seen professional nuances in the background of the developed intuition provide an opportunity to make the only right decision. Thus, the pedagogical skills of teachers who use this technology in the educational process provide tremendous effect for future professional activity. This technology activates the development of critical thinking competence.

7) The project method involves searching for the necessary information, its integrating, structuring and manufacturing of a new information product, promotes the development of skills to work with intensive information streams, choosing the main idea from them. This technology can be applied as an impetus for creative self-realization of the personality.

Own pedagogical experience suggests the necessity of using the next stages: initiation, execution, presentation delivery, project close.

Initiation: at this stage a teacher presents the idea of the project work, provides brief information about the overall project goals and assigns the tasks to the groups.

Execution: after students received instructions, the teams can begin executing the project according their assigned tasks. It is the stage where everyone actually starts doing the work: looking for necessary information and the ways to present it. Presentation delivery: this stage is devoted to the oral presenting information. 
The way, the learners present information, is chosen by the students. The focus is on the content of the information and the way the students support it. Students are free to choose different forms of material presentation: power point presentations, presentations with the pictures, making posters, usual reports.

Project Close: once all the details and tasks of project are complete and everybody agreed on discussed items, teacher can finally close the project work by brief summarizing the most important information and praising students. Encouraging students is very important and motivated technique, as project work is quite challenging task for the students, especially those who are usually shy [5].

Cooperation of students with teachers in creating projects leads to the implementation of technology cooperation and the ability to act in accordance with their interests and abilities. Besides, project work is successfully used for providing an opportunity for the students to discuss possible methods of patients' examination and treatment at the universities' clinics. In this way it contributes to the formation of such competencies as analysis and synthesis, initiative, development and project management.

8) Problematic discussions: round table, panel discussion (expert group meeting), forum, debate, etc. This technology provides opportunities for students to express their thoughts even if they are false. At the same time the teacher is supposed to guide them to the right direction. This concerns both the consideration of particular patients' problem during practical classes and thematic lectures where the teacher should encourage the students to express opinions on the topic of discussion. Since students understand the "impunity" of their mistakes in the lecture hall, they are more boldly involved in the dialogue transforming the lecture into the creative process of learning new material. It facilitates the development of different competencies like teamwork, interdisciplinary team, decision-making, problem solving.

9) Information technologies suppose the use of all possible sources of information (literature, electronic, Internet, etc.) to solve a learning problem that requires computer skills, knowledge of foreign languages. The subject of research becomes more understandable, accessible and even visualized. In addition, there is access to the polar points of view, which are not always emphasized in the university, and the possibility of personal perception which can lead to further group discussions with students and the teacher. It develops basic computer skills, informational, foreign language competencies.

10) Telemedical technologies provide the development of skills for accessing the diagnostic and counseling base of any medical institution at any time and expands the physician's ability to establish the diagnosis correctly, in time and provide adequate assistance [18]. Future doctors are aware of the possibility of feedback from their supervisors and colleagues in the future. Especially important contacts are those with other specialists, the ability to apply simulation and reconstruction of the treatment results. This technology helps facilitate the for- 
mation of competencies to manage information, basic computer skills, teamwork.

11) Distant learning is a fast, convenient, affordable and economical way of obtaining information [19]. It is successful in almost all areas, but there are a lot of discussions over its implementation in the medical field, due to concerns about deterioration in the quality of training [13]. Nevertheless, it is successfully used abroad. Research, conducted by American scientists, has confirmed that distant education can significantly enhance the theoretical aspects in addition to the traditional training of doctors [14]. The high price for providing the process and inexperienced staff are highlighted as major shortcomings of this technology [15]. Still, it is useful while forming the competence of basic computer skills and information management.

12) "Case" technology is the practice of using "cases" as means of training in the fields of law, business, medicine, education. Therefore, it is becoming popular and is promoted by foreign medical colleagues. "Cases" are very detailed, contextual, descriptive reports on teaching and learning. They are used to help future physician in understanding the specifics of clinical situations and developing skills in problem solving, filling in patients' clinical records. It is valuable to train students in establishing diagnosis. This technology is traditionally applied for teaching medical students at the universities' clinics in order to prepare them for future professional activity. They promote formation of competence in problem solving and decision-making [1]. Besides, "case" technology provides the opportunity for teachers to check dental students' level of professional competence.

13) European Credit Transfer and Accumulation System (ECTS) is mastering the educational material in thematically interconnected blocks (modules) which provide the possibility of final control over certain knowledge, skills and abilities, volume of theoretical and practical material. In dental education, each component is assessed through control in different forms: tests, theoretical surveys, the implementation of relevant practical tasks, analysis of additional methods of examination, knowledge of the toolkit and writing patients' clinical records. Such performance evaluation motivates students to improve their skills and in this way such competencies as general and professional knowledge and skills possession, application of knowledge in practice are formed.

In fact, technologies like "rescue team", "case", learning through research, project method and problematic discussions have been widely applied to the educational process of medical students since the middle of XX century, but they acquired another value with the implementation of Internet into all scientific branches.

The analysis of the influence of innovative pedagogical technologies on the development of general competencies was conducted. Future dentists (221 graduates from Bogomolets National Medical University in 2017-2018) assessed the importance of general competencies formation. The results are presented in the Table 1 . 
Table 1. The influence of innovative pedagogical technologies on future dentists' general competencies formation.

\begin{tabular}{|c|c|c|}
\hline Pedagogical technology & Competencies to form & $\begin{array}{l}\text { Self-assessment of the competency's } \\
\text { impotence by future dentists (in \%) }\end{array}$ \\
\hline \multirow{2}{*}{ Personally oriented } & Self-guided work & 74.7 \\
\hline & Problem solving & 68.8 \\
\hline \multirow{2}{*}{ Developing technology } & Analysis and synthesis of information & 62.0 \\
\hline & Self-guided work & 72.0 \\
\hline \multirow{2}{*}{ Group technology } & Interpersonal communication & 26.2 \\
\hline & Team work & 76.9 \\
\hline Formation of a creative personality & New ideas induction, (creativity) & 49.8 \\
\hline \multirow{2}{*}{ Learning through research } & Research work & 24.0 \\
\hline & Critical thinking & 82.3 \\
\hline \multirow{2}{*}{ Brainstorming/synectics } & Critical/clinical thinking & 52.9 \\
\hline & Decision making & 76.0 \\
\hline \multirow{3}{*}{ Project method } & Analysis and synthesis & 62.4 \\
\hline & Initiative & 31.2 \\
\hline & Development and project management & 21.7 \\
\hline \multirow{5}{*}{ Problematic discussions } & Teamwork & 76.9 \\
\hline & Critical/clinical thinking & 62.9 \\
\hline & Interdisciplinary teamwork & 32.1 \\
\hline & Decision making & 76.0 \\
\hline & Problem solving & 69.7 \\
\hline \multirow{3}{*}{ Information technologies } & Ability to manage the information & 42.6 \\
\hline & Basic computer skills & 41.2 \\
\hline & Critical thinking & 75 \\
\hline \multirow{4}{*}{ Telemedical technologies } & Basic computer skills & 41.2 \\
\hline & Teamwork & 76.9 \\
\hline & Interdisciplinary teamwork & 32.1 \\
\hline & Clinical thinking & 83.2 \\
\hline \multirow{2}{*}{ Distant learning } & Basic computer skills & 41.2 \\
\hline & Information management & 42.6 \\
\hline \multirow{3}{*}{ "Case" technology } & Problem solving & 69.9 \\
\hline & Decision making & 76.0 \\
\hline & Critical/clinical thinking & 96.8 \\
\hline \multirow{3}{*}{$\begin{array}{l}\text { European Credit Transfer } \\
\text { and Accumulation System (ECTS) }\end{array}$} & Basic knowledge and skills possession. & 41.2 \\
\hline & Professional knowledge and skills possession. & 75.6 \\
\hline & Application of knowledge in practice & 83.2 \\
\hline
\end{tabular}


Having conducted the research, it is obvious that future dentists realize the importance of critical/clinical thinking (96.8\%) but the important competencies like research work, initiative, development and project management are underestimated according to the results of the research: $24 \%, 31.2 \%, 21.7 \%$ correspondingly.

The data of the conducted research indicate that analyzed innovative technologies that influence substantially the large part of the general and specific competencies formation, are considered vitally important by European specialists for acquiring professional competence.

Conducted research allows to make a conclusion that the level of an educational institution is determined by the quality of innovative technologies that are effectively used in it. For higher dental education, the possibility of introducing and integrating all the innovative pedagogical technologies, mentioned above, is confirmed on the basis of the conducted research. The effectiveness of their application depends on the interaction of factors that provide the pedagogical process:

1) Competent teachers who apply innovative teaching technologies in their practice at a high level.

2) Motivation and sufficient basic training of future specialists.

3) Organizational and methodological support of the technologies introduction process.

4) Effective combination of all types and levels of pedagogical technologies.

Thus, the introduction of innovative technologies in future dentists' training will enhance the effectiveness of their professional competence formation through the development of individual competencies that can be attributed to both general and specific ones, particularly: self-guided work, creativity, research, foreign language, interpersonal communication, teamwork and interdisciplinary teamwork, analysis and synthesis, problem solving, decision making.

\section{Conclusion}

Summarizing the essential features of innovative pedagogical technologies, analyzed in the article and the predicted results of their implementation, allows to conclude that it is not appropriate to be limited to the one technology in order to form professional competence of the future dentist as a well-educated, creative person. In teaching during clinical period special attention is paid to critical thinking formation as it is the base for clinical thinking. Introduction of innovative pedagogical technologies can provide great impact upon this process. Integrated output can be achieved through the whole system, the components of which, is a set of advanced technologies aimed at the developing the personality of a future doctor. Thus, mentioned above technologies are necessary to apply into the educational process at universities' clinics in order to facilitate the future dentists' professional competence formation. 


\section{Conflicts of Interest}

The authors declare no conflicts of interest regarding the publication of this paper.

\section{References}

[1] Kulbasna, Ya., Zakharova, V. and Tkachuk, O. (2017) Improvement of Future Doctors' Foreign Language Competence Formation Methodology in the Context of Medical Emergencies. Visnyk of Lviv State University of Life Safety, 15, 209-214.

[2] Zagrinchuk, M. (2013) Preparation of Specialists in Higher Educational Institutions of Ukraine in Modern Conditions on the Basis of a Competent Approach. Medical Education, 1, 11-17.

[3] Sysoyeva, S. (2002) Pedagogical Technologies: Definition, Structure, Problems of Implementation. Continuous Professional Education: Theory and Practice, 4, 69-79.

[4] Kulbasna, Ya. and Zakharova, V. (2018) The Role of Game Technology in Advancing of Future Dentists' Professional Vocabulary Competence Formation Process. Medical Education, No. 1, 62-67.

[5] Kulbasna, Ya. and Zakharova, V. (2018) The Role of Project Work in the Process of Future Dentists' Foreign Language Competence Formation. Vestnik of Vitebsk State Medical University, 17, 87-92. https://doi.org/10.22263/2312-4156.2018.2.87

[6] Gaebl, M. (2018) Overview of Recent Bologna Developments: Implamentation Report \& Paris Communique. TAM Event: European Intergaration of Ukraine's Higher Education.

https://ihed.org.ua/wp-content/uploads/2018/09/27_11_18_Bologna-Conf_MichaelGaebel.pdf

[7] Grinova, M. (2006) Pedagogical Technologies: Theory and Practice. ASMI, Poltava.

[8] Meyer, R. Besiegelt der Europäische Qualifikationsrahmen den Niedergang des deutschen Berufsbildungssystems?

http://www.bwpat.de/ausgabe11/buechter_gramlinger_b

[9] Sysoeva, S., Aleksyuk, A., Volovik, P. and Kulchytska, A. (2011) Pedagogical Technologies in Continuous Professional Education. VIPOL, Kyiv.

[10] Taylor, E. (1994). Intercultural Competency: A Transformative Learning Process. Adult Education Quarterly, 44, 154-174.

https://doi.org/10.1177/074171369404400303

[11] Tretyak, O. (2011) Application of Innovative Pedagogical Technologies. Psychological and Pedagogical Bases of Innovative Technologies Designing of Teaching in High School. Pedagogichna Dumka, Kyiv.

[12] Muts, L. (2013) Application of Pedagogical Software Tools in Learning Process of Higher Education. Medical education, 1, 42-46.

[13] Hegge, M. (2002) Competence, Continuing Education and Compuners. J. Contin. Educ. Nurs, 33, 24-33.

[14] Kurbatov, S. (2012) Distance Education as an Essential Component of the Innovation Activity of the Modern University. Problems of Education, 1, 23-27.

[15] Moore, M. (2001) Distance Education in Health Science. Pennsylvania.

[16] Turning Educational Structure in Europe. http://turning.unideusto.org

[17] Kulbasna, Ya., Zakharova, V. and Tkachuk, O. (2016) The Development of Foreign Language and Leadership Competencies in Providing Competitiveness of Future 
Doctors. European Humanities and Studies. State and Society, 4, 260-270.

[18] “Telemedicine Today". http://www.telemedtoday.com

[19] American Center for the Study of Distant Education. http://www.ed.psu.edu/acsde 